\title{
A Case Study on Mobile-Blended Collaborative Learning in an English as a Foreign Language (EFL) Context
}

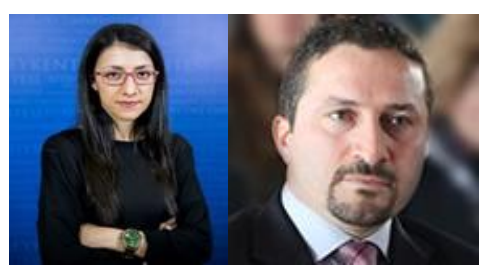

Hulya Avci ${ }^{1}$ and Tufan Adiguzel ${ }^{2}$

${ }^{1}$ Beykent University, School of Foreign Languages, ${ }^{2}$ Bahcesehir University, Faculty of Educational Sciences

Istanbul, Turkey

\begin{abstract}
As learning a foreign language poses a number of challenges for the students, it has become indispensable to search for "optimal" conditions to enhance opportunities of engaging in the target language. Within this context, the Mobile-Blended Collaborative Learning model has been integrated in and out of the classroom learning in order to enable language learners to practice English by means of collaborative, authentic language activities based on project-based learning approach. The purpose of this study was to explore the effects of using mobile instant messaging application, WhatsApp on the language proficiency of EFL students. Participants $(N=85)$ were enrolled in five upperintermediate prep classes at a foundation university in Istanbul and took part in a seven-week Project Work. Data were collected through semi-structured interviews and focus group discussions, self- and peer evaluations of group work, a rubric for assessing project work, and log files of WhatsApp conversations. Results revealed practicing English in an authentic setting where the students used the target language for a real purpose facilitated their language learning, improved their communication skills and vocabulary knowledge, and made them recognize colloquial English. Additionally, instant messaging in an informal platform for educational purposes had positive effects on their performance and the quality of their work.
\end{abstract}

Keywords: mobile learning, collaborative learning, instant feedback, foreign language learning, informal learning

\section{Introduction}

The broad use of mobile devices influences teaching and learning by enabling more flexible environments where learners can learn and practice anywhere and anytime. With the widespread ownership of mobile devices, young people search for new ways of developing their knowledge and experience of mobile technologies in out-of-school settings, which is obviously distinct from how they 
use these technologies at school (Sefton-Green, Nixon, \& Erstad, 2009). Furthermore, the use of mobile technologies has been influencing both modern communication ways and foreign language learning since situations which are rooted in daily life affect language itself (Ogata \& Yano, 2005).

Mobile technology-enhanced learning activities employed by students in formal settings are different from those in informal settings. In formal settings, technologies are usually used in a systematic, planned, and administered way to execute curricular work in public spheres. On the other hand, in informal settings, technologies are socially and collaboratively used by young people in unorganized and non-administered ways to undertake individual interests in private spheres (Lai, Khaddage, \& Knezek, 2013). Nevertheless, mobile technologies enable blending formal and informal learning by readjusting the present learning settings, which can result in improving students' learning skills and experiences inside and out of school (Faux, McFarlane, Roche, \& Facer, 2006; Linsey, Panayiotidis, \& Ooms, 2008). A report by Kukulska-Hulme, Sharples, Milrad, Arnedillo-Sanchez, and Vavoula (2009) highlighted the recent mobile learning projects conducted both in formal and informal learning environments have reinforced the evolution of technology-enhanced learning from a different standpoint. In a sense, mobile learning projects not only build a bridge between formal and informal learning, but also incorporate a small or wider online learning community including participation of teachers and family in various modes of interaction.

Furthermore, research indicates mobile technologies can facilitate the learning mechanism in formal and informal contexts with the support of collaborative activities (e.g., Sharples, Taylor, \& Vavoula, 2005; Lai et al., 2013) and reinforce both "opportunistic informal learning" and "collaborative informal learning" (Clough, Jones, McAndrew, \& Scanlone, 2008, p. 359). Concerning the use of mobile apps, successful integration of apps requires novel methods and models to ensure active participation, engagement, interaction, and collaboration among students and teachers (Khaddage \& Lattemann, 2013). Although mobile apps for teaching and learning are in their infancy, if they are integrated effectively into learning at schools, they can promote efficient teaching and feedback, thus simplifying the learning process (Khaddage, Lattemann, \& Bray, 2011).

In the EFL settings, one of the common challenges is non-native speakers of English usually experience lack of access to authentic sources for a real-life communicative purpose. Therefore, most of the EFL learners have limited exposure to the target language in real-world settings. Regarding this, language learning could be more "authentic, efficient, relevant and effective"identifying and allying with global mobile technologies (Traxler, 2013, p. 2).

This study took place in EFL classrooms to provide the undergraduate EFL students with a learning setting in which they could gain authentic language learning experiences supported with project work. The research was grounded on the Mobile-Blended Collaborative Learning (MBCL) model as a first stage to conceptualize the use of mobile technologies and applications to combine formal and informal learning (Lai et al., 2013). The basic rationale behind this model is to overcome the drawbacks of traditional foreign language education. The MBCL model puts forward three application categories including "tools for collaboration," "tools for coordination," and "tools for communication" in order for the blend of formal and informal learning (Khaddage et al., 2011, p. 419). On this basis, WhatsApp as a mobile-instant message tool, was integrated into the project work to enable the students to collaborate, coordinate, and communicate in both synchronous and asynchronous modes. This model signifies the affordances of mobile technologies in a blended and collaborative learning setting. It puts 
an emphasis on the advantages of informal learning to minimize the disadvantages of formal learning, thus creating "a more balanced and flexible learning environment" (Lai et al., 2013, p. 416). Basically, MBCL enables interaction, collaboration, sharing, and learning in informal settings unrestricted to time and location (Looi et al., 2010).

In a mobile-blended collaborative learning setting, students can be provided with various authentic tasks or activities in which they can actively participate. In this sense, project-based learning supported with mobile technologies is acknowledged as an effective way to combine both traditional face-to-face learning with informal learning (Lai et al., 2013). While engaging with real-world activities or projects, students may need scaffolding from teachers, and this is also essential to encourage students to focus on the task, the setting, and the community of learners. Through the apprenticeship process, students are urged to work in cooperation and be involved in collective attempts; likewise, they progress from a novice to an active contributor (Hung, Chee, Hedberg, \& Seng, 2005).

In a study reported by Song and Fox (2008), undergraduate English learners had a positive attitude towards consistently utilizing personal digital assistants (PDAs) as a dictionary to extend their vocabulary knowledge in an out-of-class setting. Hockly (2013) conducted a classroom-based action research with two successive groups of international EFL learners from a private language school in the UK and found most students were satisfied with using mobile devices and desired to keep learning in this manner. Some studies (Motiwalla, 2007; Plana et al., 2013) found most of the students took advantage of instant messaging and supported the use of mobile devices for educational purposes. Another experimental study by Barhoumi (2014) was carried out to evaluate the effects of mobile learning activities via WhatsApp in a blended learning course called Scientific Research Methods. The experimental group experienced two hours of in-class learning and one hour of WhatsApp mediated learning activities and the control group was exposed to only in-class learning. It was found there were positive effects on the blended course experiment composed $70 \%$ of face-to-face and $30 \%$ of online learning via WhatsApp discussions.

In conclusion, this study aimed to address the overarching research question: "What is the effect of integrating WhatsApp mobile app into a group project work in out-of-school setting on EFL students' language learning process?" Regarding the lack of specific studies on the variation of authentic language learning experiences in MBCL, as well as instant feedback via WhatsApp, this study might suggest practical implications for: (a) ensuring more opportunities of learner participation outside the school walls, (b) exploiting the benefits of colloquial or spontaneous language use in MBCL setting, and (c) enriching teaching models in different contexts for higher education EFL teachers.

\section{Methodology}

In the study, a mixed method case study was applied to gather data for an overall interpretation and investigate the data within a specific context. This research design was carried out based on its appropriateness and effectiveness for this study. The object of collecting data based on a variety of sources is to develop the theory suggesting the qualities of the case and to promote the validity to the arguments made by the researcher or the participants in the case (Stake, 2005). Accordingly, both quantitative and qualitative data sources were collected to answer the proposed research question. 


\section{Participants}

This study was carried out in the spring term of the 2014-2015 academic year at a Turkish private university in Istanbul, Turkey. The university is both a Turkish and English medium university, but a one-year preparatory English program is compulsory for all undergraduate students who are not able to achieve at least a B1+ (Intermediate) language level. Upon completing B1+ level, the students can progress to B2 (Upper-Intermediate) level. In the study, a purposeful sampling method was used in the selection of the participants to elicit the potential of the students at B2 level of English. Participants included 85 EFL students (42 females and 43 males) who were enrolled in the English preparatory program and ranged in age from 18 to 24 years. Participating students were from five B2 level classes with 15-20 students in each class. The common characteristics of the participants were described as following: (a) the students were volunteered to take part in the project; (b) they were assumed as experienced users of current mobile technologies, especially Web 2.0 technologies or social media apps mediated via smartphones through which they were accustomed to communicating in text-based instant messaging online chat platforms in their native language; and (c) they would need to practice English more by making use of their knowledge, experiences, and language skills effectively in authentic settings. As a result, it would enable to elicit their potential at their target language level by performing a project work with their peers collaboratively.

\section{Project Work Description}

Participants were assigned to create a class magazine as an out-of-school activity with the support of WhatsApp throughout the seven-week module. The major objective of the project work was to provide the students with the opportunity of experiencing project-based, authentic, contextualized, meaningful, engaging, and collaborative mobile-blended learning. Moreover, the rationale behind creating a class magazine was it is one of the common projects carried out in language classes.

There were 22 WhatsApp chat groups with at least three students in each group. While the instructor as the administrator of each group facilitated the whole process, the students determined their group members and roles voluntarily, and further worked in cooperation toward the group success. An upper-intermediate course book was provided as an instructional material for the students to benefit from the proposed three units (beginnings in life, social issues, and great expectations). Overall, the students were expected to: (a) choose particular theme-based topics from the real-life issues; (b) determine their content, genre, and target audience; (c) use written and visual materials (e.g., short articles, anecdotes, interviews, illustrations, images, etc.); (d) gather information for each topic area; (e) design layout using Microsoft Word/Publisher or other programs; (f) form 20-40 pages with a cover illustration; and (g) lastly, print their magazine.

As for the instructional plan of the module, three sessions including in-class, face-to-face, and online instruction mediated via WhatsApp were conducted by separating the seven-week project duration into the systematic sessions regarding the ongoing module in the university. The first session (two weeks) was carried out to cover the predetermined units in the course book and facilitate the comprehension of each unit with various activities in the classroom. In the meantime, after the instructor formed the WhatsApp groups, the students initiated their group discussions on the selection of the unit and asked their questions to clarify the project scope and objectives via WhatsApp. The second session (one week) was focused on examining various real magazines to recognize essential elements of a typical magazine through both in class and WhatsApp discussions. 
The third session (three weeks) was allocated all the groups to design their magazine maintaining the process via WhatsApp. The final session (one week) was executed for the assessment of the project work.

\section{Data Collection Procedures}

Data were gathered from: (a) a peer evaluation form, (b) a scoring rubric in the quantitative phase, (c) log files of WhatsApp chats, and (d) interviews in the qualitative phase. A peer evaluation form was developed to offer the students the opportunity to evaluate the performance and quality of the project work for themselves and their fellow group members, and to provide feedback to each other at the end of the project. The peer evaluation form included 10 criteria (e.g., took an active role during the project, contributed effectively to the group discussion). The content validity of the items was examined by an experienced faculty member in the field and two experienced EFL instructors. It asked each student to indicate to what extent they agreed or disagreed on the specified criteria by using a five-point Likert scale ranging from 1 (strongly disagree) to 5 (strongly agree). Each student was rated by themselves and three or four group members, generating multiple ratings of a single student, as a result, enabling the reliability of the peer evaluation form itself to be evaluated. The Cronbach's alpha coefficients of self-ratings were found $r=.90$ and peer ratings were found $r=.97$, indicating a very good internal consistency reliability for the scale.

An analytic scoring rubric was used as an assessment tool to identify the students' performance and their finished product at the end of the project. The rubric consisted of certain criteria including "planning and preparation," "design," "content," "collaboration," and "delivery and presentation" which were determined using feedback from the faculty colleagues and an experienced expert in the field. The descriptions of the dimensions were scaled through labels as following: "needs improvement," "satisfactory," "good," and "excellent," and specific performance criteria being observed were indicated for each label. After all 22 groups submitted their project work by the predetermined deadline, the researcher and a 15-year experienced EFL instructor from the same university, scored the overall performance and product of each group as independent of each other.

Semi-structured focus group discussions and individual interviews were conducted to add in-depth insights into the study. The interview guide comprised 15 questions for individual interviews and 10 for the focus groups. The questions were based on several key issues, such as instant feedback, group work, out-of-school activity, WhatsApp, and collaboration related to the research question. For instance, "How did you find the experience of working in the group out of school hours?," "What were the benefits of the project in terms of language learning?," and so on. Further, the interviews were held face-to-face in the mother tongue of the participants (Turkish) in two distinct methods, specifically with two focus groups, one with 16 participants while the other had 15 participants, and 10 one-to-one interviews. At least two students from each class were randomly chosen for the interview. The interviewees' responses were audio-recorded and transcribed verbatim for the further analysis.

Log files obtained from WhatsApp group chats were generated by the system software showing all conversations separately among the 22 groups and the instructor. All were systematically arranged according to the group codes. The log files indicated all of the processes the students experienced, thus providing clear outcomes for evaluating the effectiveness of instant feedback via WhatsApp and observing the interactions between the students and the instructor. Moreover, the mastery and application of collocations is highly fundamental for the EFL learners to deal with any written 
messages and listening conversations. For this reason, in terms of the use of the target language, it was mainly focused on the use of collocations in their conversations. Further, it seems rather hard to acquire or utilize collocations for high-level language learners as well. Therefore, in the analysis of those log files, the collocations the students used in their chats were identified and compiled.

\section{Data Analysis Procedures}

Regarding the self- and peer evaluation process, each student was expected to assign scores to themselves and their group-mates respectively. Based on the overall mean scores obtained from selfand peer ratings, Pearson correlation analysis was performed to determine the degree of relationship between them. Subsequently, the analytic scoring rubric was utilized to analyze data in the quantitative inquiry. Two raters separately scored each criterion in the rubric on a scale of 1 to 4 and each score was summed up to reach a final score. Ultimately, inter-rater reliability was determined using Pearson's $r$ to measure the correlation between the scores of the two raters.

In the analysis of the interviews, each of 10 one-to-one interviews and two focus group interviews, were analyzed through the content analysis approach. Lastly, 22 log files were analyzed by examining mobile text transcripts derived from those log files in terms of certain linguistic features including the structure of the sentences, the use of particular word items (collocations in particular) or formation, and functional and colloquial language used in a range of situations.

\section{Results}

\section{Qualitative Results}

In respect of the in-depth analysis of the convergence of focus groups and individual interviews, eight main emergent themes were generated based upon the high frequency of the common responses to the overall 15 semi-structured interview questions.

Management of the project work. Certain key points were touched upon by the students such as working out the scope of the project at first and taking initial steps including determining duties and responsibilities among group members, deciding on genre, and selecting topics. Based on the observations and remarks of the students, some groups appeared to experience lack of comprehension of the object of the project at the beginning as well as certain challenges such as poor time management and difficulty dealing with technical part of the project work, plus being unable to execute the project process properly. To illustrate, two students reported as follows: "We didn't talk...in the first week because we couldn't understand the project. The only thing we did was to go over the topics and units....In the second week we were able to decide on topics" (Female Student 1 Class 3), and "First, we determined our group members, then we tried to decide on the subject of our magazine...related to the main subject each of us chose our own topic...finally we shared the tasks during the process" (Male Student 2 - Class 2).

Reinforcement of various skills. The students were able to bring their skills forward while working on the project with their friends. Although they were assumed to have already acquired certain skills such as language skills, computer skills, and communication skills, through cooperative working relationships, they had the opportunity to experience new skills and realize their potential. 
The group work in the authentic learning environment seemed to enable them to encounter many blended skills consisting of research skills, project management skills, and transferable and interpersonal skills. Based upon that, some students reported as follows: "I learnt how to make a group work, collaborate with people...produce something collectively....the spirit of team work initiated in our minds and helped me to bring a new perspective" (Male Student 3 - Class 1), and "The most important thing I learned was to become patient....the project contributed me to improve my relationships with people ... thanks to the project I made many friends and felt more in peace in class" (Female Student 4 - Class 4).

Impacts on interpersonal learning. Working in groups during out-of-school hours appeared to have positive impact on the students' interpersonal learning by providing more interaction among the students, giving them the sense of responsibility for performing a task in collaboration, encouraging active participation, and exposing them to gain real-world experiences in the target language. Related to the following comments, being aware of their final work to be assessed by their teachers, influenced their performance positively as well: "The sense of responsibility triggered me too much because you were not at school but you had to do something related to the school and also it was not an ordinary homework, so we all took it very serious" (Female Student 5 Class 2), and "It was a good experience; I knew my friends better during the process and developed many different ideas while working out-of-school hours” (Female Student 6 - Class 4).

Cooperation in formal and informal settings. Since the students were expected to get actively involved in collaborating with each other, they utilized the opportunities of making consistent online and face-to-face communication by meeting outside or at school, and contacting their group members and the instructor anytime and anywhere. To illustrate, the comments of some students were indicated as follows: "Outside the school we arranged our own tasks together. Individually we were always in contact with each other in our WhatsApp group, for example regularly everyone joined the conversation, asked questions" (Male Student 7 - Class 1), and "We couldn't have any chance to meet in somewhere to talk about the project because of the school hours...in the evenings communicated a lot about the details and discussed them via WhatsApp" (Male Student 19 - Class 5).

Pursuit of goal-oriented strategies. Several basic issues were mentioned by the groups related to the procedure of creating a magazine such as planning, designing, determining the content, and collaborating in group work. Therefore, the students applied certain strategies to facilitate their group work, and based on their remarks, it was found out some commonly used strategies were brainstorming, choosing favorite topics, searching for authentic magazines, consulting to experts in the field, making exchange of ideas, and utilizing technology to some extent. Regarding the explanations above, some students reported as follows: "We made brainstorming while determining our unit and topics by looking for real magazines and checking what they included ... tried to discover some different ways so that we could create some original and professional product" (Female Student 9 - Class 1), and "I benefited from the internet a lot in my search for information and images about my topics. I also checked out some real magazines to get a general idea about the design and layout of magazines" (Female Student 10 - Class 3).

Ease of communicating via WhatsApp. A number of advantages of using WhatsApp as a collaboration and communication tool were asserted. Most distinguishing among these advantages were providing contact anytime and anywhere between group members and the instructor, 
maintaining punctual and clear decision making process, enabling synchronous and asynchronous communication, and having timesaving feature. To support these points, some comments are indicated as follows: "It was very practical; otherwise we had to send messages to each other individually; it would take so much time. However, in WhatsApp everyone was involved in the group and could see all sent messages" (Female Student 11 - Class 3), and "It was useful; I shared what I thought about the project with you and my friends immediately...when an idea came to my mind, I'd forget it later but via WhatsApp I could convey my messages on time” (Male Student 12 - Class 2).

Positive effects of instant feedback. Most of the students expressed their satisfaction about receiving instant feedback via mobile phone during the project work. Concerning the prevalent positive effects of instant feedback on group work, certain notable effects were specified including promoting effective exchange of opinions, asking questions anytime and anywhere, alleviating any potential concern, and helping manage time. "The best advantage was out teacher was in the WA group. As we felt like a fish out of water, having no idea about how to create a magazine, we had an opportunity to ask questions to her anytime" (Female Student 13 - Class 4), and "It gave me an opportunity not to make a lot of mistakes...to become aware of my mistakes and correct them... asked questions to our teacher as well as taking her advice at some critical points" (Female Student 14 Class 5).

Engagement in language activities. The students gained the opportunity of using the target language for the benefit of carrying out their project, and practicing more in English. Furthermore, the students experienced using English for real world purposes such as doing research in English, discovering colloquial English words and phrases while texting on WhatsApp, making background readings from various materials, writing paragraphs or essays on their topics, compiling information and resources, engaging group discussions, and benefiting from multimedia. "(I) had a chance to experience daily English... (I) was able to find many different components of language, reading articles helped me a lot...you can see everything from formal to informal language" (Female Student 15 - Class 1), and "(I) improved my English in terms of speaking skill by chatting via WA. I did a lot of research about my topic...I've not had any experience to do such in English, but the project contributed a lot to my English" (Female Student 34 - Class 5).

Based on the log files, a total of 1711 posts were sent by the participants during the project. The average number of posts sent by each student ( $n=80$ ) was 21.3 (see Table 1); however, only five students were inactive, merely viewing the posts sent in the group. As the initial three weeks were allocated mostly for in-class activities related to the project work, the students started their conversations via WhatsApp in the following weeks. The average numbers of posts during the rest of the weeks were 58.9 (week four), 28.8 (week five), 7.4 (week six), and 4.7 (week seven). Those results showed the majority of the postings were sent during week four and the group discussions maintained weekly over the course of the project.

Table 1

Descriptive Statistics of the Number of Posts per Class

\begin{tabular}{lcc}
\hline Class $\quad$ \# of groups & $\begin{array}{c}\text { \# of } \\
\text { group posts }\end{array}$ & $\begin{array}{c}\text { Percentage } \\
\text { of total }\end{array}$ \\
\hline
\end{tabular}




\begin{tabular}{llll}
\hline $1(n=19)$ & 4 & 450 & 26,3 \\
$2(n=16)$ & 4 & 268 & 15,6 \\
$3(n=17)$ & 4 & 472 & 27,5 \\
$4(n=18)$ & 5 & 199 & 11,6 \\
$5(n=20)$ & 5 & 322 & 18,8 \\
\hline
\end{tabular}

Regarding the content analysis of log files, two types of lexical collocations, which were commonly used, were identified in the collection of conversations: verb and preposition, and verb and noun collocations (see Table 2). Most particularly, "make" as a verb was examined due to the students' variety in their use of lexical collocation "make + noun." As an example, one student posted "We are planning to make interviews with tradesmen." and another student responded "Yes, I checked it out, but we've not made any progress yet."

Table 2

\section{Sample Lexical Collocations Recognized in the Log Files}

\begin{tabular}{ll}
\hline Type & \multicolumn{1}{c}{ Example } \\
\hline Verb + Noun & $\begin{array}{l}\text { arrange meeting, catch points, use imagination, } \\
\text { give attention, deliver project, pay attention, } \\
\text { confuse one's mind, take as a mission, do research }\end{array}$ \\
\hline $\begin{array}{l}\text { Verb + Noun } \\
\text { (make) }\end{array}$ & $\begin{array}{l}\text { make search, make progress, make up one's mind, } \\
\text { make improvement, make arrangement, make } \\
\text { decision, make discussion, make an interview }\end{array}$ \\
\hline Verb + Preposition & $\begin{array}{l}\text { concentrate on, enquire about, write down, put } \\
\text { forward, insist on, belong to, run out, figure out, } \\
\text { get along with, search for, decide on, throw away, } \\
\text { deal with, cut out }\end{array}$ \\
\hline
\end{tabular}

Although some students made certain grammatical mistakes while texting, they were usually able to use those collocations properly. Furthermore, it was noticed the most common verb-noun miscollocations were used between "do search" or "do research" and "make research" or "make search." To illustrate, "I think we should do search before start" or "Who will make researches about places where we go?" Aside from those collocations, certain texting slang words were identified in the conversations: phonetic replacements, abbreviations, and acronyms including "u," for "you," "thx" for "thanks," "gonna" for "going to," "me2" for "me too," and so on.

\section{Quantitative Results}

By means of the peer evaluation form, the participants evaluated their own performance and their peers' at the end of the project. Correlations were computed between self- and peer ratings in student group work (see Table 3). The results suggested that 18 out of 30 correlations were statistically significant in a two-tailed test, in that 14 of them at the .05 level and four at the .01 level. Overall, the findings indicated there were high and weak correlations between self- and peer ratings.

Table 3

Pearson Correlation Matrix Between Self- and Peer Ratings in Student Group Work $(N=85)$

\begin{tabular}{rlcr}
\hline & Peer 1 & Peer 2 & Peer 3 \\
\hline Self 1 & -.086 & .375 & .115
\end{tabular}




\begin{tabular}{llll} 
Peer 1 & .110 & $.685^{*}$ \\
Peer 2 & & .239 \\
\hline Self 2 & $.581^{*}$ & $.613^{*}$ & .386 \\
Peer 1 & $.768^{* *}$ & $.645^{*}$ \\
Peer 2 & & $.601^{*}$ \\
\hline Self 3 & & .211 & .139 \\
Peer 1 & & $.582^{*}$ & $.662^{*}$ \\
Peer 2 & & & $.970^{* *}$ \\
\hline Self 4 & $.583^{*}$ & $.657^{*}$ & $.695^{*}$ \\
Peer 1 & $.642^{*}$ & $.762^{* *}$ \\
Peer 2 & & & $.729^{* *}$ \\
\hline Self 5 & $.724^{*}$ & -.035 & .423 \\
Peer 1 & & .319 & $.744^{*}$ \\
Peer 2 & & & $.519^{*}$ \\
\hline Note. ${ }^{*} p<.05{ }^{* *} p<.01$ (two-tailed tests). &
\end{tabular}

Regarding the rubric analysis, as a result of the assessment of the consistency of the scores of the two assessors, the correlation between the Rater 1 and Rater 2 scores was found to be moderate, $r(44)=$ $+.442, p<.05$, two-tailed since five outliers were identified with some great differences, which were more than 5 , between two scores given to these groups: $8,12,15,16$, and 22 . However, by removing those five outliers in the data, the correlation was found to be statistically significant, $r(44)=+.855, p$ $<$.o1, two-tailed.

\section{Discussions}

This study aimed to investigate the effect of using instant messaging application enabling instant feedback throughout the process of project work on the EFL prep school students' language improvement in a mobile-blended learning setting. Concerning the findings of the study, it was indicated the students had the opportunity to use the target language in an authentic group work project, in particular, had a chance to practice vocabulary knowledge, including various topic-based words and lexical collocations, and distinguished between formal and informal language via instant text messaging system during the process of creating their magazines.

Having the experience of texting in English through discussions and conversations, the students usually paid attention to write their sentences accurately and choose appropriate words regarding the standard writing conventions. Therefore, through communicating in an informal setting, the students not only reinforced what they had already known about the basics in English, but also they were able to differentiate between "slang, texting lingo and correct English" (Russell, 2010, p. 223). On the other hand, the students were not restrained from the use of text messaging language including abbreviations or contractions, emoticons, omission of punctuation, non-standard expressions, and spellings as the focus was on efficiency: getting one's message on time and meaningfully as possible. The students reported they tried to negotiate and make exchange of ideas in the target language, pursuing a mutual goal, planning and managing multiple issues, communicating information, and ideas effectively to complete their project work. However, due to a lack of experience in working collaboratively to achieve a common goal, some students mentioned having difficulty agreeing with 
certain decisions, and maintaining consistent interaction with their peers. On the other hand, they also reported that they managed to come to terms on any disagreements in the end.

Moreover, the students participated in rating each of their group member's contribution to the success or failure of their group, including themselves. However, the results showed that some self-ratings were poorly correlated with peer ratings or vice versa and indicated no consistent frame of being higher or lower that the others' assessment. The underlying reasons for such poor correlations could be associated with having different opinions or approaches towards the evaluations of the performance of each group member in terms of the sense of team spirit, the willingness of each peer to collaborate, the satisfaction with the quality of their work, and the active participation in discussions, as well as being cooperative regarding the individual differences in personality. Based on the observations, some group members behaved as free riders, not actively getting involved in the group work and leaving most of the work to other group members. In addition, few students reported as being not satisfied with working together with some of their friends in the same group. Thus, they appeared not so voluntary to take active roles and expected from the others to compensate for their lack of effort. Through peer evaluation, the hardworking students caught the opportunity of dealing with such free riding issues by giving low scores to their peers, although every group member received the same score based on the assessment of their final product.

Further, the results from the evaluation scores of the project work demonstrated there was a moderate correlation between the scores given by two instructors. This suggested that the raters met on less common ground on their rating, giving highly different scores from each other. Therefore, the raters seemed not to agree on some criteria in the assessment of several project works. On the other hand, there was a close relationship between the self- and peer assessment and the raters' assessment regarding the quality of project works, the contribution of each group to the project, and the overall group performance. This was also supported with the reports of the students during the interview. As an example, one student reported "I learnt how to make a group work, collaborate with people...(and) produce something collectively" underlying the related theme, reinforcement of various skills. Another student remarked, "(o)utside the school we arranged our own tasks together" illustrating another theme, cooperation in formal and informal settings.

As for the effects of receiving mobile instant feedback via WhatsApp, from the remarks of the students, it appeared the most notable benefit of using WhatsApp was "time management," which provided great convenience to communicate anytime and anywhere and facilitated the collaborative group work. In essence, the constant social interactions among the groups influenced the project process positively and eliminated the barrier between the formal setting of the classroom system and informal setting of the social networking tool. Moreover, Gillingham and Topper (1999) emphasized the effectiveness of instant messaging on the learning process through collaborative learning or social interactions. In a study examining the classroom communication between the high school students and the teachers using WhatsApp, the academic advantages of WhatsApp were indicated by the participants as follows: "the accessibility of learning materials," "teacher availability," and "the continuation of learning beyond class hours" (Bouhnik \& Deshen, 2014, p. 217). However, whilst most students expressed as their satisfaction about regularly maintaining their conversations in the mobile platform, few students touched upon that from a different perspective and reported that it had a negative impact on their conversation amongst their peers. As an example, one student remarked "it might kill sincerity among the groups as the teacher was also involved in each group” because some 
groups may have pretended to work hard, but they did not in reality. Due to this reason with fairness and equity in the group work, the students' perception of group members might have been adversely affected, as evidenced with the poor correlations between some self- and peer ratings as well as the related theme above mentioned as the cooperation in formal and informal settings.

Some issues might also be essential to note about this study. The study was carried out with the participants of B2 level EFL learners. To extend the findings of the study, a wider range of participants having diverse linguistic levels could be involved in a prospective study. In addition, a more representative sampling frame could have been utilized in the selection of the focus group and individual interview participants. Another issue is the students had the opportunity of improving their word knowledge, but they might have utilized the words they had already known. Nevertheless, the active use of words and collocations in the target language was taken into consideration to encourage the practice of different sorts of words. Finally, the privacy issues associated with the use of WhatsApp could bring about concern for some students due to the presence of the teacher in the group, thus, could be one factor to regard the use of mobile devices for educational purposes.

\section{Conclusion}

In conclusion, the previous reviews on mobile technologies and learning are mostly related to the use of these technologies in several particular curriculum areas. More specifically, upon tracing back to the literature on the issue of conducting project-based learning (PBL) in a mobile-blended learning environment, there are relatively few satisfactory empirical studies, in particular, in the scope of foreign language learning. Therefore, the results of this study could be beneficial for guiding prospective research studies in the current area and making contribution to the discussions of mobile learning. The findings of this study indicated that the EFL students favored improving their integrated language skills by involving in a variety of learning experiences, which provided meaningful interaction for real world purposes. In addition, nearly all of the students had positive attitudes towards participating in synchronous and asynchronous conversations with their peers and instructor for academic purposes. Besides language skills, the students developed their interpersonal and collaborative skills; however, the lack of literature about the subject of providing instant feedback mediated via a mobile application in an out-of-class language learning activity has enabled the rationale for this study. Thus, it could be suggested a well-designed language course supported with mobile technologies can encourage more effective and collaborative learning, not only in the classroom, but also outside the classroom, considering the needs and learning outcomes of the EFL students.

\section{References}

Barhoumi, C. (2014). The effectiveness of WhatsApp mobile learning activities guided by activity theory on students' knowledge management. Contemporary Educational Technology, 6(3), 221-238.

Bouhnik, D., \& Deshen, M. (2014). WhatsApp goes to school: Mobile instant messaging between teachers and students. Journal of Information Technology Education: Research, 13, 217-231. 
Clough, G., Jones, A. C., McAndrew, P., \& Scanlone, E. (2008). Informal learning with PDAs and smartphones. Journal of Computer Assisted Learning, 24, 359-371.

Faux, F., McFarlane, A., Roche, N., \& Facer, K. (2006). Futurelab: Learning with handheld technologies. Retrieved from https://telearn.archives-ouvertes.fr/hal-00190331

Gillingham, M. G., \& Topper, A. (1999). Technology in teacher preparation: preparing teachers for the future. Journal of Technology \& Teacher Education, 7(4), 303-321.

Hockly, N. (2013). Designer learning: The teacher as designer of mobile-based classroom learning experiences. Monterey, CA: The International Research Foundation for English Language Education. Retrieved from http://www.tirfonline.org/wpcontent/uploads/2013/11/TIRF_MALL_Papers_Hockly.pdf

Hung, D., Chee, T.S., Hedberg, J.G., \& Seng, K.T. (2005). A framework for fostering a community of practice: Scaffolding learners through an evolving continuum. British Journal of Education Technology, 36(2), 159-76.

Khaddage, F., \& Lattemann, C. (2013). iTeach welearn via mobile apps 'a Case Study in a Business Course'. In R. McBride \& M. Searson (Eds.), Proceedings of Society for Information Technology \& Teacher Education International Conference 2013 (pp. 3225-3233). Chesapeake, VA: AACE.

Khaddage, F., Lattemann, C., \& Bray, E. (2011). Mobile apps integration for teaching and learning. (Are Teachers Ready to Re-blend?). In M. Koehler \& P. Mishra (Eds.), Proceedings of Society for Information Technology \& Teacher Education International Conference 2011 (pp. 25452552). Chesapeake, VA: AACE.

Kukulska-Hulme, A., Sharples, M., Milrad, M., Arnedillo-Sanchez, I., \& Vavoula, G. (2009). Innovation in mobile learning. A European perspective. International Journal of Mobile and Blended Learning, 1(1), 13-35.

Lai, K. W., Khaddage, F., \& Knezek, G. (2013). Blending student technology experiences in formal and informal learning. Journal of Computer Assisted Learning, 29(5), 414-425.

Linsey, T., Panayiotidis, A., \& Ooms, A. (2008). Integrating the in-classroom use of mobile technologies within a blended learning model. Proceedings of the 7th European Conference on e-Learning, Agai Napia, Cyprus, 2, 119.

Looi, C., Seow, P., Zhang, B., So, H., Chen, W., \& Wong, L. (2010). Leveraging mobile technology for sustainable seamless learning: A research agenda. British Journal of Educational Technology, 41(2), 154-169.

Motiwalla, L. F. (2007). Mobile learning: A framework and evaluation. Computers \& Education, 49(3), 581-596.

Ogata, H., \& Yano, Y. (2005). Knowledge awareness for computer-assisted language learning using hand- helds. International Journal of Learning Technology, 5(1), 435-449. 
Plana, M. G. C., Escofet, M. I. G., Figueras, I. T., Gimeno, A., Appel, C., \& Hopkins, J. (2013, July). Improving learners' reading skills through instant short messages: A sample study using WhatsApp. $4^{\text {th }}$ World-CALL Conference, Glascow.

Russell, L. (2010). The Effects of Text Messaging on English Grammar. Retrieved from http://www.ehow.com/list_5828172_effects-text-messaging-english-rammar.html

Sefton-Green, J., Nixon, H., \& Erstad, O. (2009). Reviewing approaches and perspectives on 'digital literacy.' Pedagogies: An International Journal, 4, 107-125.

Sharples, M., Taylor, J., \& Vavoula, G. (2005). Towards a theory of mobile learning. In H. van der Merwe \& T. Brown (Eds.), Mobile technology: The future of learning in your hands, mLearn 2005 book of abstracts: 4th World Conference on mLearning (p. 58). Cape Town: mLearn.

Song, Y., \& Fox, R. (2008). Uses of the PDA for undergraduate students' incidental vocabulary learning of English. ReCALL, 2O(3), 290-314.

Stake, R. E. (2005). The art of case study research. Thousand Oaks, CA: SAGE.

Traxler, J. (2013). Mobile learning for languages: Can the past speak to the future? Monterey, CA: The International Research Foundation for English Language Education. Retrieved from http://www.tirfonline.org/wpcontent/uploads/2013/11/TIRF MALL Papers Traxler.pdf

Athabasca

University

(). 0 